\title{
THE APPLICATION OF PHENOMENOLOGICAL METHODOLOGY FOR DESIGNING PILE FOUNDATION IN PORT STRUCTURES
}

Paweł Więcławski

Gdańsk University of Technology, Faculty of Civil and Environmental Engineering, Poland

\begin{abstract}
It is of utmost importance in the design process that a suitable, safe and concurrently economic solution be chosen. Issues connected with foundations require adopting a special approach. Soil is a composite medium, and it is essential to describe as precisely as possible the interaction taking place between the subgrade and the structure. There are many design methods of pile foundation that are based on in-situ test of soils. As a result of incessant development of the pile installation technology, the results obtained with design methods used to date do not assure the required accuracy, and consequently the values of pile load capacity are not sufficiently accurate. A partial solution to this problem may be applying the observation method. Based on assumptions of phenomenology as a science that enable cognition of natural and mathematical phenomena, a procedure has been developed for projecting loading-settlement dependencies for Vibro piles installed in port areas in Poland. Those areas are characterised by similar soil and water conditions, as well as soil genesis and parameters. This procedure enables estimating the limit of load capacity values with much better accuracy than the hitherto used direct methods. The full range of the $s(Q)$ function also enables the possibility of designing structures allowing for stringent criteria of admissible settlements having a specified value.
\end{abstract}

Keywords: phenomenology, observation method, pile foundation, Eurocode 7, limit load capacity

\section{INTRODUCTION}

The development of port infrastructure depends to a large extent on the development of maritime navigation and transport. Major difficulties in this respect include significant implementation costs and lack of certainty related to safe building of structures. Variable elements are environmental impacts, such as waves, wind and water, and soil conditions. If the soil contains organic layers, mud, or silt, pile foundations need to be adopted $[2,7,9]$. The design methods comprise in the first place the method of limit states, in which the ultimate limit state (ULS) and the serviceability limit state (SLS)[14] are assessed. When commencing designs of pile foundations, firstly the in-depth analysis of relevant parameters related both to the soil, and to the characteristic features of the piles should be performed. As regards the subgrade, we should have at our disposal a complete identification of conditions in which the construction is to be founded. Attention should be drawn to: soil types, groundwater tables, natural state of stresses, filtration properties, and strength parameters. As for pile parameters, the elements which should be determined include: quality of the concrete mix, pile installation method, possibility of occurrence of deviations caused by the occurrence of soil layers of considerable compressibility, 
and roughness and rigidity of the pile [5,. Allowing for those aspects is not simple if we have at our disposal only simplified analytical approaches. To quote K. Terzaghi [3]: "Unfortunately, soils are made by nature and not by man, and the products of nature are always complex... As soon as we pass from steel and concrete to earth, the omnipotence of theory ceases to exist. Natural soil is never uniform. Its properties change from point to point while our knowledge of its properties is limited to those few spots at which the samples have been collected. In soil mechanics the accuracy of computed results never exceeds that of a crude estimate, and the principal function of theory consists in teaching us what and how to observe in the field". The obtained results should be considered to be "crude estimate". To obtain more accurate results, the standard PN-EN 1997-1:2008 allows the possibility of adapting the observation method called "active designing" according to $[8,15]$ :"...is a continuous, managed, integrated, process of design, construction control, monitoring and review, which enables previously defined modifications to be incorporated during or after construction as appropriate. All these aspects have to be demonstrably robust. The objective is to achieve greater overall economy without compromising safety". This method is a combination of tests and analyses of the building structure and the soil with ongoing measurements of the behaviour of the building structure and the subgrade not only during the execution of construction works, but also during operation. The projection executed in this way, when limited to local conditions of soils with the same genesis, physical properties and strength parameters, enables achieving a more accurate reflection of the actual state. The paper presents a methodology for projecting the functioning of piles on the areas of Szczecin and Gdynia ports. Pursuant to rules of precise, economic and safe designing, a correlation has been defined between in-situ parameters of the soil and pile behaviour under the impact of vertical loads. The defined empirical dependencies enable the determination of the full settlement-load curve for the analysed pile based on the cone resistance $\mathrm{q}_{\mathrm{c}}$ obtained from CPT probing. The option of assessing the full range of pile settlement provides the opportunity to make complex use of designing conditions based on stringent criteria of admissible settlements. The process of universalisation and the nature of interdependencies arise from observations and analyses of variating particular parameters comprised by the analysis. Due to the existence of a common part of each of the parameter configurations, it is possible to devise an outline of the phenomenon and to work out universal and practical correlations. Thus it is consistent with the assumptions of the observation method and, concurrently, of the phenomenological approach.

\section{SOIL CONDITIONS OF RESEARCH FIELDS}

The analysis was performed for Vibro piles situated on the areas of port facilities. The research fields were on the premises of the Szczecin and Gdynia ports (Fig.1).
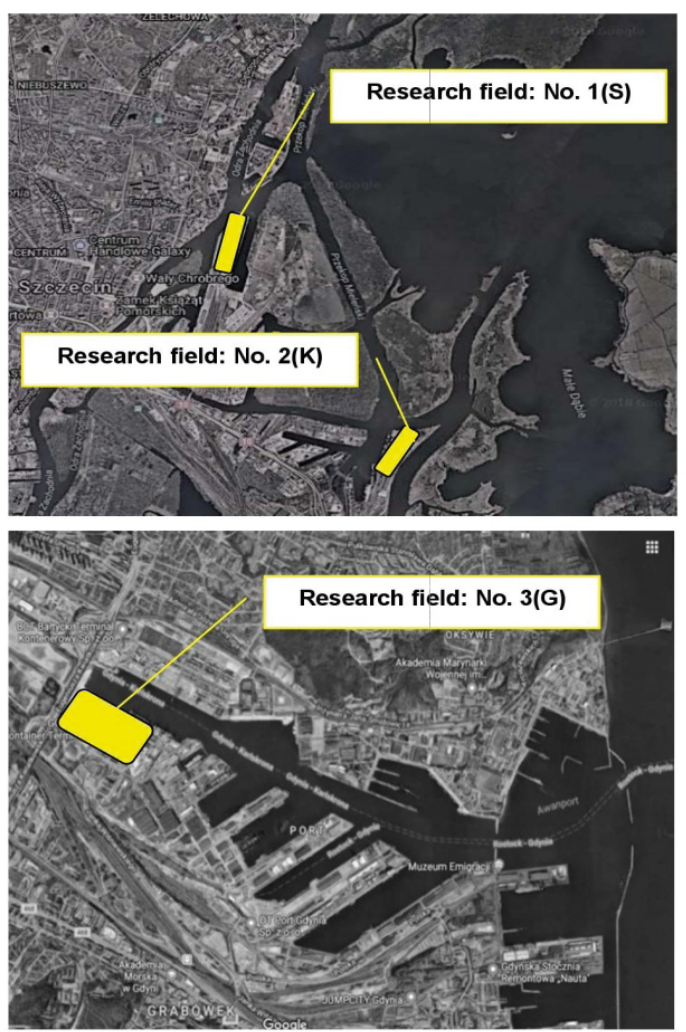

Fig.1. Situation of research fields in Port of Szczecin (up) and Port of Gdynia (down)

The testing scope comprised: geological boreholes, static CPT probing of the soil, and static pile load tests (SPLT). The analysis covered 36 Vibro piles, 9 CPT tests, and 8 geological boreholes (Fig. 2).
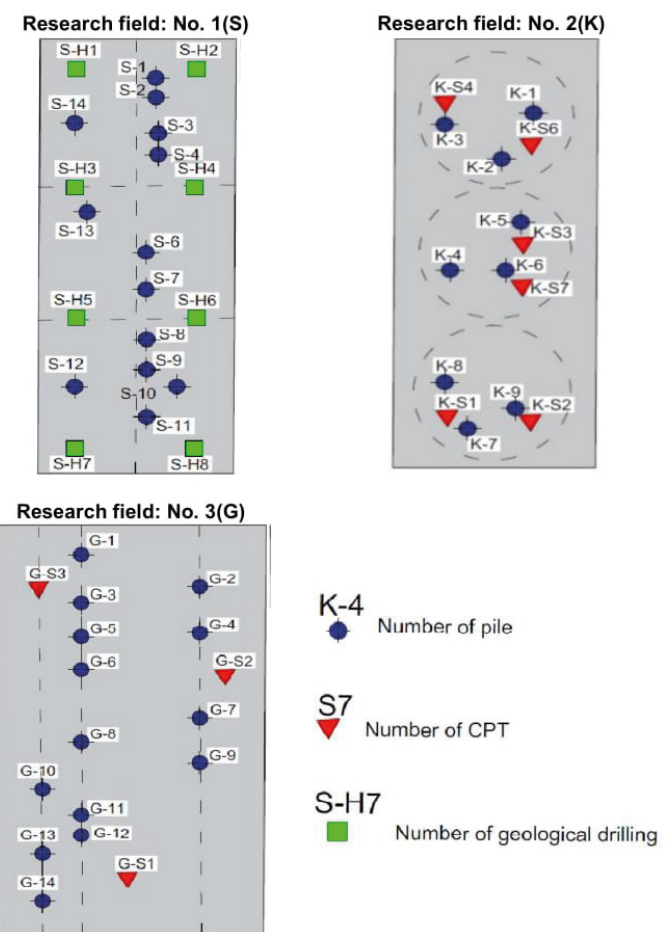

Fig.2. Distribution of research points 
Research field No. 1(S). Field investigations enabled ascertaining that the soil contains Quaternary and Pleistocene formations. Subsoils are covered by a layer of uncontrolled embankments formed as a result of land management. These are predominantly sandy embankments, locally of mud with an admixture of concrete, gravel and stones. Their maximum thickness is $2.7 \mathrm{~m}$. At a depth ranging from 8.0 to $12.0 \mathrm{~m}$ occur riverine sands covered by series of mud with peat layers. The thickness of the entire organic deposit series ranges from 4.0 to $8.0 \mathrm{~m}$. Below lies a series of deposits consisting of medium and fine sand in uncompacted state and medium dense state. The oldest deposits ascertained in the soil are Pleistocene water glacial formations, and medium and fine sand in compacted state (Fig.3). The bases of the planned Vibro piles have been founded in this layer.

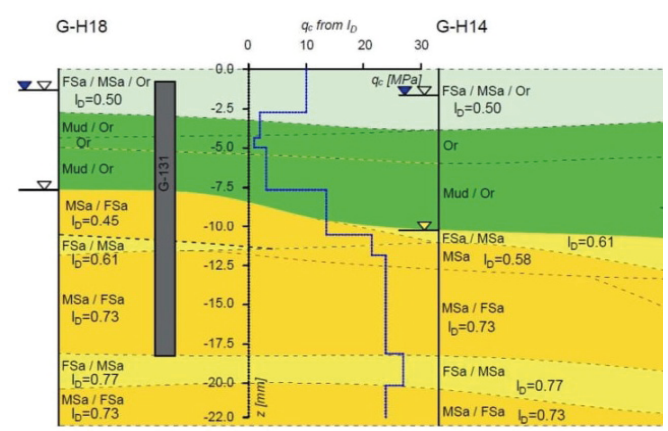

Fig.3. Characteristic geological section of the area of Research field No. 1(S)

Research field No. 2(K). The conducted tests of the soil and CPT (Fig. 4) have shown that directly under the surface lies a layer of embankments predominantly consisting of slag with admixture of debris and mineral soils. Under the embankments, fine sand has been ascertained. Sandy soil is in medium dense state. Deeper, there is a series of mud deposits, formed as silt, aggradate mud, and peat. Such soils lie as a rule $10.0 \mathrm{~m}$ below the land surface. Underneath is a series of non-cohesive soils, fine sand, where pile bases are founded.
CPT No. K-S1

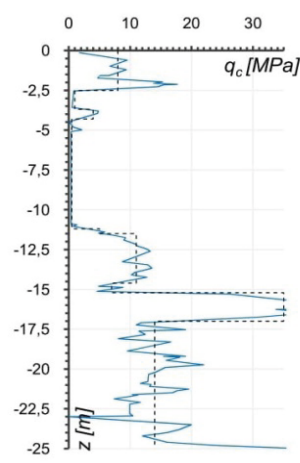

CPT No. K-S3

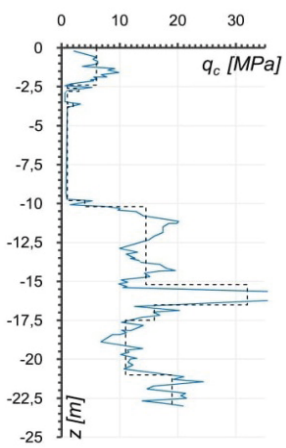

Fig.4. Characteristic results of CPT testing on the area of Research field No. 2(K)

Research field No. 3(G). Ground investigations and CPT probing (Fig.4) have shown that the surface part is made up of embankments consisting of fine sand with organic admixtures. Locally under the embankment layer lie organic soils such as peats and mud of maximum thickness of $1.0 \mathrm{~m}$. The subsoil consists of Quaternary deposits, such as fine sand, either compacted or of medium compaction and compacted, with layers of medium sand.
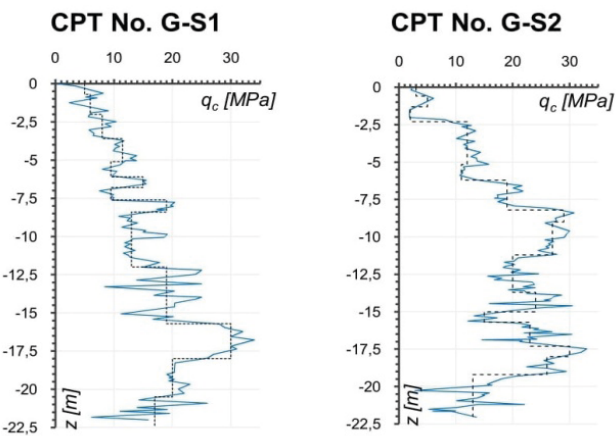

Fig.5. Characteristic results of CPT testing on the area of Research field No. 3(G)

A common element for the analysed areas is the genesis of soil conditions. The soil structure is a consequence of the accumulation of Quaternary sand materials, caused by the Northern Polish glaciation and the development of the Baltic Sea coastal zone. Weak layers comprise organic soils, such as mud and peats.

\section{PHENOMENOLOGY AS VERIFICATION METHOD OF SETTLEMENT AND DESIGNING OF FOUNDATION PILES}

Phenomenology is a direction of deliberations and analyses; in Greek the word phainomenon means "anything that manifests itself". The phenomenological method is an observation and descriptive method with emphasis on observation, and its elements comprise values of direct experience and intuition. It is a method of a specific nature that provides direct knowledge concerning "the substance of things". The method consists of seeking solutions by way of applying free conceptual variation and intentionality, i.e. a trend, which in each individual case is oriented towards something. According to E. Husserl, the author of the phenomenological approach, the accuracy of the analysed case may be achieved by implementing the postulate of the so-called theoretically uninvolved description. The concept is comprised of three basic elements: (1) adoption of an objectivistic approach, focused entirely on the studied structure, (2) exclusion or reduction of any knowledge that could originate from the existing scientific theories, and (3) ruling out convictions originating from tradition [6]. Its central thesis on cognition of a phenomenon by its specific values is adopted for the needs of mathematical and natural cognition. The conducted analysis is based on the above guidelines and its objective is to define the interaction of the soil medium with the axially loaded pile. This interaction is depicted by the load - settlement (Q-s) dependence obtained on the basis of the static load test (SPLT)[12]. 


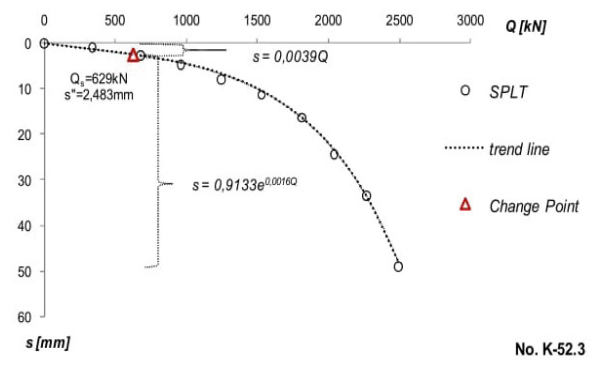

Fig. 6. Mathematical description of Q-s dependence

When analysing a set of curves, attention has been drawn to changes taking place in the nature and course of the Q-s dependence in specific soil conditions. A characteristic feature is the two-phase nature of the function. Each of the curves may be presented as consisting of the linear part and the exponential part, with the Change Point as a specific element in the mathematical description of phases (Fig. 6). Coordinates of the Change Point $\left(Q_{s}, s^{\prime \prime}\right)$ depend on pile geometry and soil parameters, represented in the analysis by cone resistance $\mathrm{q}_{\mathrm{c}}$ on the CPT probe (Fig. 7.). Based on this assumption, correlations have been defined that enable determination of the theoretical curve Q-s (Fig. 8. - Fig. 10.)

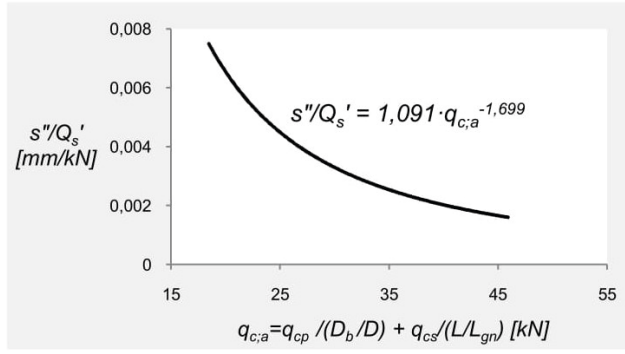

$\mathrm{q}_{\mathrm{c} ; \mathrm{a}}-$ average value of resistance $\mathrm{q}_{\mathrm{c}}$;

$q_{c p}$ - average value of resistance $q_{c}$ under pile base to the depth equal to pile diameter;

$q_{c s}-$ average weighted value of resistance $q_{c}$ along the pile side surface;

$D$ - diameter of pile:

$D_{b}$ - diameter of pile base

$\mathrm{L}-$ total pile length;

$\mathrm{L}_{\mathrm{gn}}-$ pile length in bearing soil $\left(\mathrm{q}_{\mathrm{c}}>5 \mathrm{MPa}\right)$

$Q_{s}^{\prime}$ - abscissa, abscissa of Change Point;

s" - ordinate, coordinate of Change Point;

Fig. 7. Correlation of soil parameters and directional coefficient of settlement curve

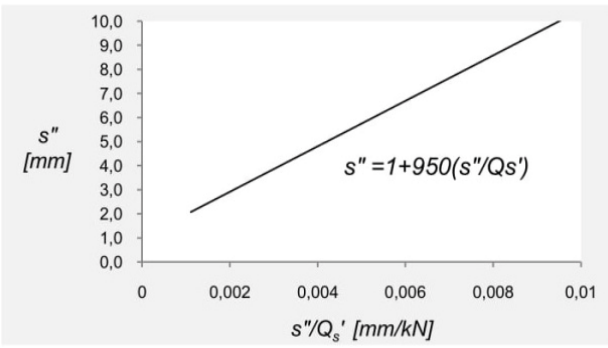

Fig. 8. Relation between Change Point coordinates

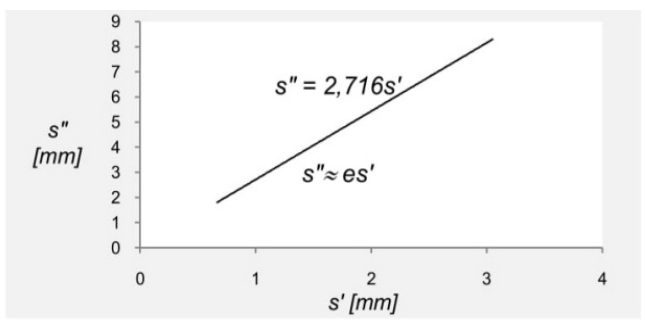

s'- basis of exponential function

Fig. 9. Relation between the basis of exponential function and the Change Point ordinate

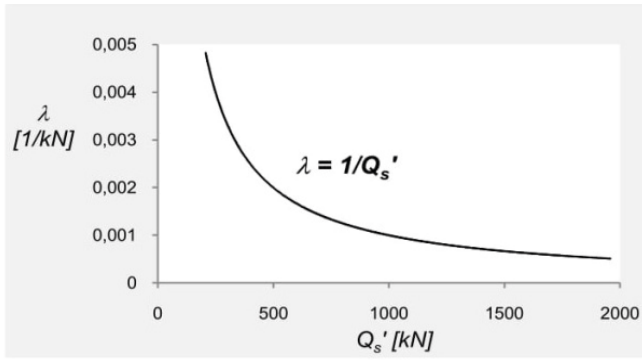

$\lambda$ - exponent of exponential function

Fig. 10. Relation between the exponent of exponential function and the Change Point abscissa

Based on the correlations shown in Figs. 7 through 10, the linear phase equations (I-II) and the exponential phase (III-IV) should be determined for the $s(\mathrm{Q})$ function. Before generating Q-s characteristics, the value of load Q' (also $Q_{s}$ ) must be reduced by adopting the correction coefficient, which depends on the averaged value of cone resistance $\mathrm{q}_{c ; \mathrm{a}}$ (Table 1.)

Table 1. Values of correction coefficient

\begin{tabular}{|c|c|}
\hline Value of averaged resistance- $\mathbf{q}_{\boldsymbol{c} ; \mathbf{a}}$ & Correction coefficient $-\mathbf{F}_{\mathbf{c}}$ \\
\hline$<30 \mathrm{MPa}$ & 1.1 \\
\hline$\geq 30 \mathrm{MPa}$ & 1.2 \\
\hline
\end{tabular}

\section{ASSESSING THE INTERACTION OF PILE FOOTING WITH SOIL}

Geotechnical designing of piles includes the selection of the type, length and diameter of the pile for the analysed soil conditions. It is necessary that the condition of the ultimate limit state be met, i.e. the bearing capacity of the pile in the soil be greater than the calculated impact effect. The bearing capacity of the pile is delimited by dividing the characteristic load by the safety coefficient $\gamma_{t}$, the value of which is assumed depending on the adopted design approach. The characteristic load capacity is delimited on the basis of the ultimate bearing capacity and should enable the determination of the characteristic load capacity with a likelihood of $\mathrm{p}=0.95$. In practical terms, we do not have at our disposal a sufficient number of delimited ultimate bearing capacity values to perform statistical analysis. Use is being made of correlation coefficients $\mathrm{x}$, which depict directly the 
distribution functions considered as appropriate for pile load capacity determination methods specified in standard PN-EN 1997-1:2008 [4,14] (Fig. 11.). The developed procedure enables determination of the value of the ultimate load capacity.

Table 2. Examples of determination of Q-s curve

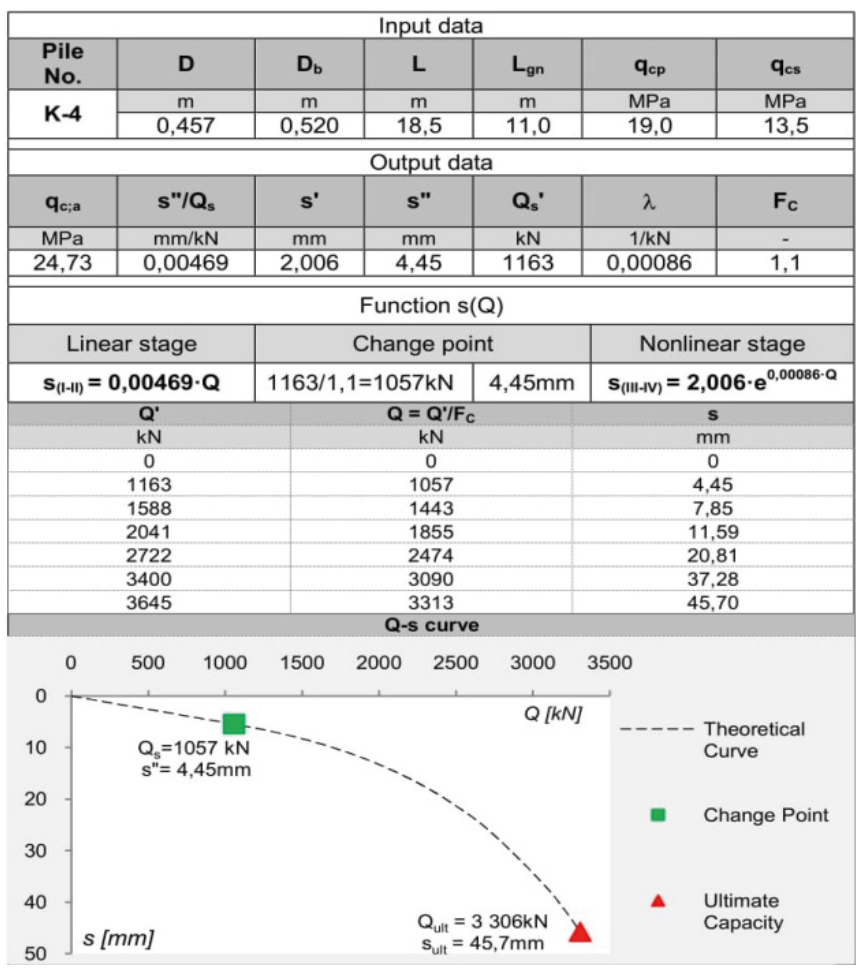

Pursuant to PN-EN 1997-1:2008, it has been assumed in the presented examples that the ultimate limit state occurs for the settlement equal to $10 \%$ of pile diameter [14] (Table 2.). In accordance with PN-EN 1997-1:2008, the testing should be repeated until it becomes possible to define the limiting bearing capacity of the pile. Based on an analysis for Vibro piles it has been ascertained that for this particular technology, the interpretation of the static load test (SPLT) according to the hitherto traditions has clearly become insufficient. The scope of loading from SPLT does not enable the determination of the value of the pile ultimate load capacity, and this in turn hinders verification of design methods and the execution of the proper statistical analysis. The convergence of the calculated and measured bearing capacity values was studied for loads conforming to maximum settlement from static load test.

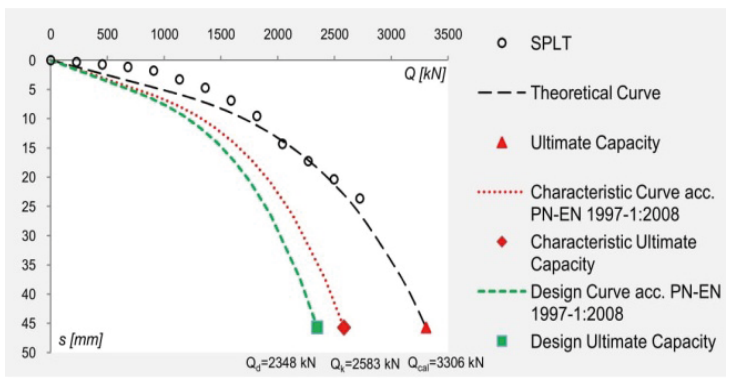

Fig.11. Values of ultimate bearing capacity pursuant to PN-EN 1997-1:2008
The statistical analysis comprises a trial that included 36 piles. It has been found that the load capacity values calculated for $22 \%$ of piles have been overestimated in relation to the measured values (Fig. 12.). By adopting the procedure specified in standard PN-EN 1997-1:2008 for calculating design values for all the piles, it was possible to obtain a safe load bearing value. The minimum safety reserve is $10 \%$ (Fig. 12.).

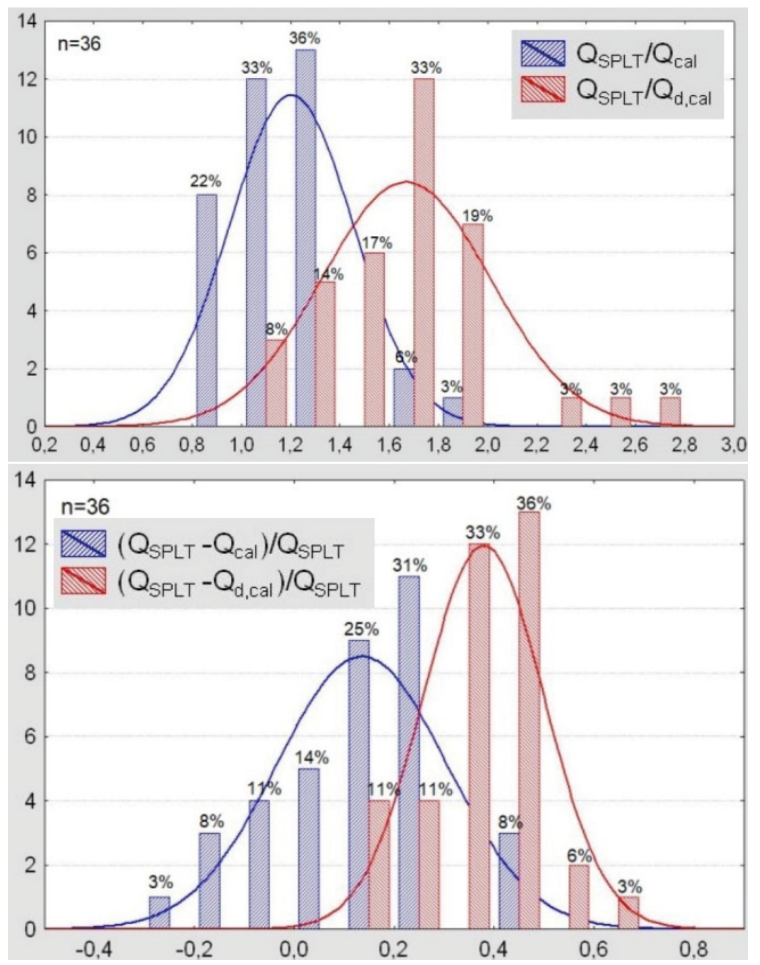

Fig. 12. Relation between calculated and measured load capacity values

\section{SUMMARY AND CONCLUSIONS}

The advantage of applying Eurocode 7 [14] is the possibility of making use, both for design and verification needs, of an arbitrary method based on any domestic practise in use to date [5]. The method discussed in this paper is of an empirical nature and has been based on assumptions of phenomenology. An element of particular importance is the Change Point in the interaction of an axially loaded pile with the subgrade, defined on the basis of CPT results. A unique feature of the procedure is clear and simple possibility of completing the determination of the $s(Q)$ function. This enables a more accurate assessment of theoretical pile load capacity as compared to other direct methods based on results of CPT. Comparing the limit load capacity values calculated with methods of LPCP, Gwizdała-Stęczniewski $[10,11,13]$, or according to PN-EN 1997-2:2008 [14,15], enabled reaching the conclusion that the values based on the developed procedure are closer to actual ones. This conclusion continues to apply even after the adoption of standard safety coefficients. In popular methods use is made of high coefficients of global safety. For 
methods used in Europe, the value of coefficients ranges from 1.5 even to $3.5[1,11]$, depending on soil conditions, applied piles, or type of construction. The results obtained based on phenomenological dependences are similar to the values obtained from the static load test. This has a considerable impact on the economic and optimal designing of pile foundations. If the full Q-s curve is available, it is possible to adopt for design needs the values of critical loading or limit loading and settlements which correspond to strictly defined required interaction criteria of the foundations and the entire facility. These requirements constitute a crucial aspect in designing port infrastructure, including foundations for specialist technical structures such as tanks, silos, or gantry cranes.

\section{BIBLIOGRAPHY}

1. Bustamante M., Gianeselli L.: Pile Bearing Capacity Prediction by Means of Static Penetration CPT. Proceedings of 2nd European Symposium on Penetration Testing, Amsterdam, 1982.

2. DeRuiter J., Beringen F. L.:. Pile Foundations for Large North Sea Structures. Marine Geotechnology, 1979.

3. Goodman R. E.: Karl Terzaghi: The Engineer As Artist. Amer Society of Civil Engineers, 1998.

4. Gwizdała K., Brzozowski T., Więcławski P.: Calculation aspects used in Eurocode 7 for pile foundation. From Research to Design in European Practice. Bratislava, Slovak Republic, June 2-4, 2010.

5. Gwizdała K., Więcławski P.: Polish experience in the assessment of pile bearing capacity and settlement of the pile foundation. Baltic Piling Days, Estonia, Talin, September $3-5,2012$

6. Husserl E.: The Crisis of European Sciences and Transcendental Phenomenology. Northwestern University Press, 1970.

7. McClelland J.: Design of deep penetration piles for ocean structures. J. Geotech. Eng. 1974.

8. Nicholson D., Tse C., Penny C.: The Observational Method in ground engineering-principles and applications. Report 185, CIRIA, London, 1999.

9. Randolph M. F., Design consideration for offshore piles. Proc. Of the Conference on Geotechnical Practice in Offshore Eng., ASCE, 1983.

10. Salgado, R.; Lee, J., Pile Design on Cone Penetration Test Results. Final Report, FHWA/IN/JTRP-99/8, 1999.
11. Tomlinson M.J., Pile Design and Construction Practice. Wyd. E\&FN SPON, Londyn, 1994.

12. Więcławski P. Methodology for estimating settlement of Vibro piles based on CPT. Gdansk University of Technology 2016.

13. Wroth C.P., The Interpretation of in situ Soil Tests. Geotechnique, Vol. 34, No 4, 1984.

14. PN-EN 1997-1:2008: Geotechnical design, part 1. General rules. Eurocode 7, Brussels, 2008.

15. PN-EN 1997-2:2008: Geotechnical design, part 2. Ground investigation and testing. Eurocode 7, Brussels, 2008.

\section{CONTACT WITH THE AUTHORS}

Paweł Więclawski

e-mail:pawwiecl@pg.edu.pl

Gdańsk University of Technology

Faculty of Civil and Environmental Engineering

Gabriela Narutowicza 11/12

80-233 Gdańsk

Poland 